\title{
Innovation and commercialization in public health care systems: a review of challenges and opportunities in Canada
}

This article was published in the following Dove Press journal:

Innovation and Entrepreneurship in Health

II September 2015

Number of times this article has been viewed

\section{Meghan Sebastianski ${ }^{\prime}$ \\ Donald Juzwishin' \\ Ulrich Wolfaardt ${ }^{2}$ \\ Gary Faulkner ${ }^{3}$ \\ Kevin Osiowy ${ }^{2}$ \\ Peter Fenwick ${ }^{2}$ \\ Tracy Ruptash'}

'Health Technology Assessment and Innovation, ${ }^{2}$ Major Initiatives, Alberta Health Services, ${ }^{3}$ Research and Technology Development, Glenrose Rehabilitation Hospital, Edmonton, AB, Canada

Video abstract

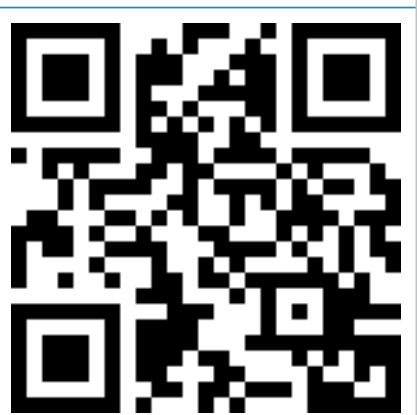

Point your SmartPhone at the code above. If you have a QR code reader the video abstract will appear. Or use: http://youtu.be/80wKEdbxigk
Correspondence: Donald Juzwishin Health Technology Assessment and Innovation, Alberta Health Services, Suite 1200, North Tower, I0030- 107 Street, Edmonton, Alberta T5] 3E4, Canada

Tel + I 780735074 I

Fax +I 7807350873

Email don.juzwishin@

albertahealthservices.ca
Abstract: Innovation has become the new panacea for addressing a plethora of health care delivery issues. In this review, we examine the relationship between health technology assessment and technology commercialization in the Canadian health care system to identify opportunities to improve access and quality of health care delivery. A selected literature review identifies the causes and contributing factors to the innovation and sustainability challenges facing our publicly funded health care system. Three case examples from Alberta in Canada provide insight into the barriers and opportunities encountered at different stages of technology diffusion and commercialization, illustrating that innovation and sustainable public health care can be complementary, not incompatible. This review provides guidance to future health care policy and decision makers on advancing thinking and practice about innovation, assessment, and value.

Keywords: innovation, commercialization, Canada, public health care

\section{Introduction}

The purpose of this review is to provide a glimpse of the Canadian landscape on the challenges and opportunities associated with the tensions emerging between the objectives of delivering cost-effective health care services and nurturing an environment that stimulates and sustains innovation, specifically commercialization. These tensions are exacerbated by the fact that Canadian health systems, compared to peers, do not appear to deliver outcomes commensurate with expenditures. The allocation of public funds requires that the prudent choice be in favor of the proven intervention rather than a promising, yet unproven, intervention and that the responsibility for funding commercialization be shouldered by the private sector. Without meaningful mutually supportive processes and pathways between public health care delivery and private sector commercialization, opportunities for clinical and economic benefit are potentially foregone.

Evidence of clinical effectiveness and the incremental cost-effectiveness ratio (ICER) have been the primary tools in health technology assessment (HTA) to inform decision makers as to whether a new health care intervention should receive public funding. In the marketplace, discounted cash flow (DCF) has been the predominant method to assess whether venture capital should be directed toward a promising investment. This review illustrates that success in achieving cost-effective health care delivery and stimulating innovation through public participation in commercialization can be commensurate. We identify through a selected literature review, as well as the exposition and analysis of three case studies lessons, that a publicly funded health care system may reconcile the tension between its roles in the delivery of publicly 
accountable health care services, innovation development, and commercialization.

\section{Methods}

To unbundle the issues surrounding the root causes of these tensions, we undertook an opportunistic literature review focused on Canada, with limited referral to international sources. One of the authors (DJ) compiled a collection of papers over the past 5 years (January 2010-January 2015; 142 publications) through snowball sampling of publications on health care innovation addressing contemporary issues in Canada. An additional search was conducted (MS) using published (PubMed, Embase, and Biosis Previews) and gray literature (Canadian Agency for Drugs and Technologies in Health [CADTH] Grey Matters) on topics related to innovation diffusion, commercialization, health care innovation, and implementation in Canada (January 2000-March 2015; 2,091 publications identified). Finally, three case examples from Alberta in Canada are presented to illustrate the external and internal dynamics associated with health care innovation, as well as the role of HTA and innovation to create an environment that mitigates risk. First, the Locator Device Project (LDP) examines the piloting of a consumer product, a wearable global positioning system (GPS), with early-stage dementia patients in a community. Second, the example from the Glenrose Rehabilitation Hospital (GRH) describes two closely related products that were developed between industry, academia, and health care providers to help rehabilitate patients with mobility issues. Third, the Linac-MR represents a technology in the experimental validation stage, being prepared for release to a commercial venture, in which the health care provider owns the majority of the intellectual property (IP). These three projects represent innovation at three stages of diffusion and commercialization. Each of the cases is described with respect to its origins and objectives, the approach that was taken, the challenges and issues encountered, and finally lessons learned from the experience. The observations and results from the case studies, coupled with the literature review, were synthesized into an approach to help health care providers, innovators, governments, and industries not only to understand the challenges and issues but also to provide a possible way forward.

\section{Limitations}

Our focus is on the Canadian public health care system, which by international comparisons is characterized as publicly funded, disaggregated (the 13 separate provinces and territories have constitutional responsibility for funding, administering, and delivering health care to their citizens) ${ }^{1}$ and not delivering outcomes commensurate with funds expended. ${ }^{2}$ Generalization from this study to other jurisdictions and in populations such as children or those with rare diseases should therefore be done with caution. The literature review was opportunistic rather than systematic, and the three case studies were selected because they captured the experiences of the authors and illustrated the varied challenges that had to be overcome. There may, therefore, be a selection bias; however, we hope to mitigate this bias through open disclosure of all case dimensions.

\section{Literature review}

Four landmark publications by the Conference Board of Canada on technological innovation, regulation, innovation procurement, and sustainability confirmed what many Canadians in the health care field already suspected: that Canada has fallen behind in the pursuit of innovative and sustainable health care..$^{3-6}$

\section{Causes and contributing factors}

Innovation in Canada is often impeded by current policy and legislation. Government regulation and evidence-informed reimbursement are necessary to ensure public safety and to achieve desirable economic and societal outcomes, ${ }^{4}$ however, they also act as a constraining force against innovation. Labor agreements, collective agreements, and procurement policies can constrain implementation and discourage new innovations. ${ }^{7}$ While provincial and federal governments have tried to encourage innovation through changes to "policies, regulations, legislation, and taxation", these can be slow and lengthy processes in a field that is fast paced and risk averse. $^{4,8}$

Canada's public health care system is also hindered by the disconnect between innovation and procurement. ${ }^{9}$ Annual expenditures for supplies and services are not being translated into the development and implementation of innovation, support for which is necessary for an improved and sustainable health care system. ${ }^{4}$ A survey by the Conference Board of Canada suggests that procurement policies are being driven by fiscal constraint rather than the idea of value generation and long-term benefits to the system. ${ }^{4}$ Purchasing decisions focused on the cost of the device rather than on the impact on quality of care are much more common and can actually result in increased system costs due to increased admissions or length of stay. ${ }^{9}$ In an effort to corral costs, many hospitals have turned to group purchase organizations to extend their 
buying power, a process that favors larger companies that can offer competitive prices but that severely limits smaller companies with innovative products. ${ }^{9}$ The Canadian health care system has also proven unresponsive in removing devices that have become embedded in routine, despite one device's lack of both clinical efficacy and cost-effectiveness, resulting in stagnation. ${ }^{9}$ Disinvestment processes for cost-ineffective and clinically low-value interventions need to be implemented to address this weakness in the health care system. ${ }^{10}$ In short, procurement processes, both for investment and disinvestment, need to support value-based and evidenceinformed decisions that consider growth and sustainability of the health care system alongside cost control.

\section{Emerging solutions and responses}

Over the past decade, custodians of the health care system in Canada have begun to shift their approach toward management of health care innovations in response to insatiable demands and rapidly increasing health care costs. This occurs as Canada and others move toward a "knowledgebased economy" in an effort to improve the health system and patient outcomes through a process of value-based and evidence-informed decision making and commercialization of health research and innovation. ${ }^{11}$ The province of Ontario recently released the results of the Health Innovation Council review ${ }^{12}$ identifying six strategies for implementation of innovation:

- Establish an office of health innovation strategist;

- Appoint innovation brokers to connect innovators with resources;

- Invest in made-in-Ontario technologies;

- Accelerate the shift to strategic value-based procurement;

- Create incentives and remove barriers to innovation; and

- Optimize the pathways to adoption and diffusion of innovation.

The recommendations of the Health Innovation Council identify, at a high strategic level, the enabling ingredients for advancing the integration of commercialization into health care research and delivery. The major challenge is how, operationally, to achieve this.

\section{Harmonization}

Discussions around how to improve health care outcomes, increase cost-efficiency, and foster innovation have generally centered on strengthening the relationship between industry, regulators, and payers, although patient's families and communities are starting to be included. Harmonization - adjustments to create efficient and coordinated processes through increased communication and collaboration would decrease uncertainty in the innovation process and provide quicker market access for health technologies. ${ }^{13}$ Tripartite meetings to align timelines and logistical aspects could significantly reduce duplication efforts and unnecessary resource use. ${ }^{14}$ With regular contact and collaboration between the stakeholders, including manufacturers, policy makers, and clinicians, silos that are commonly found throughout the health care system could be dismantled, enabling progress that would serve to strengthen innovation and support sustainability while improving patient and health system outcomes. ${ }^{14}$

The MaRS EXCITE program (Excellence in Clinical Innovation Technology Evaluation) in Ontario is the first formal harmonization process in Canada that is open and explicit. EXCITE connects innovators in the health technology industry with academic researchers. ${ }^{15}$ This collaboration allows development of high-quality, relevant evidence to support the acceptance and implementation of new products by illustrating its value to stakeholders. By undertaking a harmonized process, EXCITE moves the HTA into the premarket process, which improves the likelihood of success in the open market. ${ }^{16}$ Success for harmonization depends largely on open and honest communication and collaboration between multiple stakeholders. It is imperative that the legalities around the sharing of confidential information between parties are balanced with the transparency demanded by the public. ${ }^{17}$

\section{Health technology assessment}

Canada has been on the forefront of the implementation of HTA $^{18}$ with the establishment of the Agence d'évaluation des technologies et des modes d'intervention en santé (AETMIS) in the late 1980s when the HTA first began to expand worldwide. ${ }^{19}$ AETMIS was a precursor to the Institut national d'excellence en santé et en services sociaux (INESSS), which is one of the few HTA agencies that cover the spectrum from health to social services. ${ }^{19,20}$ In fact, the province of Quebec is unique throughout the world as the only jurisdiction where University hospitals are required to implement HTA methods. ${ }^{19}$ The CADTH was established in 1990 to serve the needs of the federal and provincial governments, ${ }^{21}$ and other Canadian jurisdictions have also invested in centers that support HTA and innovation, including the Toronto Health Economics and Technology Assessment at the University of Toronto and the Programs for Assessment of Technology in Health at the McMaster University. In Alberta, the Health Technology Decision Process has been in place since 2003, 
building on the strength of academic programs such as the Institute of Health Economics and, at the Universities of Calgary and Alberta, coupled with policy mechanisms to assess and adjudicate on public funding of new health care interventions. $^{22}$

The published evidence suggests that Canada's health care systems are ripe for the introduction of enablers and incentives to close the innovation gap by using partnerships with innovators, which will simultaneously improve health care delivery and create wealth. Next, we examine three cases to illustrate our point.

\section{Alberta Health Services: approaches to innovation}

In an effort to advance health innovation and make the health care system more sustainable, Alberta Health Services (AHS), Canada's first integrated, coordinated, and centrally managed health care system, amalgamated the province's 12 separate health authorities into a single governance board to provide 4.5 million Albertans a more streamlined health care system. The transition has been challenging on several accounts. However, the opportunity presented for modernizing health care delivery was seen as a necessary rupture to stimulate change. ${ }^{23}$ One of the organization's primary initiatives, development of Strategic Clinical Networks, was introduced to create an environment to stimulate the translation of research and innovation to improved health care practice, outcomes, and cost-effectiveness. ${ }^{24}$ The opportunity is also being taken to review and redesign the health technology decision process to be more relevant and timely to the health care provider communities. The following three provincial projects illustrate Alberta's approach to innovation at different levels. A comparison of the case studies is outlined in Table 1.

\section{LDP: a health care provider perspective Objectives}

The LDP was designed to assess the usability of market-ready wearable GPS technology for early-onset dementia clients and their caregivers. Developed in support of Alberta's strategy to support seniors to age in place and live in the community as long as safely possible, this study established how GPS technology offers solutions for clients, caregivers, the health care system, and the community.

\section{Approach}

The LDP (2013-2015) is an AHS research project in collaboration with Alberta Innovation and Advanced Education and the University of Alberta, Faculty of Rehabilitation Medicine, Department of Occupational Therapy. ${ }^{25}$ A literature review (2000-2013; 488 citations) informed the desired technology specifications and the Contracting, Procurement, and Supply Management Department posted a request for proposal to industry for a GPS solution related to dementia. Dementia clients and their caregivers were provided with wearable GPS technology (a watch, necklace fob, or a shoe insert) for a period of up to 1 year. The evaluation team collected data on user acceptance and satisfaction, while the study team collaborated with the vendor to improve the technology based on real-world experience.

\section{Challenges and issues}

A precursor to the LDP, the Continuing Care Technology Innovation (CCTI) project recommended that Home Care Case Managers recognize the role that technology can play to support clients and families at home. ${ }^{26}$ Ultimately, however, even in sites where the technology was trialed and demonstrated success, the technology was not adopted and Home Care practices did not change. One reason for health systems being slow to implement innovations is probably that while the government works to drive local innovation, support local entrepreneurs, and meet local health care needs, health expenditures are tightly managed and are not commensurate with advancing innovative progress. Health care systems are bound by accountability to be prudent with provincial funds and high-quality objective data in support of adoption and implementation of new technology are sought. As a result of the outcome of CCTI, the LDP Working Group included representation from the Health Technology Assessment Group.

Overall, the project identified several challenges to which we had to be responsive:

- Establishing the capacity in AHS to manage the project from inception to conclusion. This required assigning a full-time project manager.

- Integrating the LDP into operational realities due to competing operational priorities; eg, cost containment.

- Facilitating the collaboration and participation of multiple parties (internal and external).

- Ethics harmonization; ethics approval across two regions in AHS.

- Setting aside resources for evaluation.

- Following up with knowledge translation and implementation following successful interim results.

- Adapting the implementation plan to maintain momentum. 
Table I Comparison of three case studies

\begin{tabular}{|c|c|c|c|c|c|}
\hline Case study & Approach & Barriers & Lessons learned & Innovation benefits & $\begin{array}{l}\text { Health system } \\
\text { benefits }\end{array}$ \\
\hline $\begin{array}{l}\text { Locator Device } \\
\text { Project (health } \\
\text { care provider } \\
\text { perspective) }\end{array}$ & $\begin{array}{l}\text { Prospective usability } \\
\text { study of device in } \\
\text { target population }\end{array}$ & $\begin{array}{l}\text { Questions and issues } \\
\text { about usability of } \\
\text { the technology, } \\
\text { procurement } \\
\text { guidelines, ethics, } \\
\text { and privacy }\end{array}$ & $\begin{array}{l}\text { Technology impact } \\
\text { on clients, providers, } \\
\text { practice, and service } \\
\text { provision; evaluation } \\
\text { informs lessons }\end{array}$ & $\begin{array}{l}\text { Technology developers and } \\
\text { care providers } \\
\text { used real experience } \\
\text { to improve device }\end{array}$ & $\begin{array}{l}\text { Usability and } \\
\text { evaluation results } \\
\text { informing approaches } \\
\text { to implementation } \\
\text { challenges at the } \\
\text { policy, operational, and } \\
\text { organization levels }\end{array}$ \\
\hline $\begin{array}{l}\text { Glenrose } \\
\text { Rehabilitation } \\
\text { Hospital } \\
\text { (institutional } \\
\text { perspective) }\end{array}$ & $\begin{array}{l}\text { Innovation in } \\
\text { collaboration with } \\
\text { technical university } \\
\text { and SMEs to solve } \\
\text { clinical challenges }\end{array}$ & $\begin{array}{l}\text { Resource constraints, } \\
\text { IP management, and } \\
\text { access for SMEs } \\
\text { within the health } \\
\text { system }\end{array}$ & $\begin{array}{l}\text { Need for harmonization } \\
\text { of technical innovation } \\
\text { experience, industrial } \\
\text { push, and clinical pull } \\
\text { to address an unmet } \\
\text { need that has } \\
\text { commercial value }\end{array}$ & $\begin{array}{l}\text { Access to end users, } \\
\text { experience for students, } \\
\text { support, and feedback at } \\
\text { all stages of innovation } \\
\text { pathway; more likely } \\
\text { commercial success }\end{array}$ & $\begin{array}{l}\text { Design of new approach } \\
\text { wherein the health } \\
\text { system becomes an } \\
\text { economic engine; change } \\
\text { in the culture }\end{array}$ \\
\hline $\begin{array}{l}\text { Linac-MR } \\
\text { (medical device } \\
\text { perspective) }\end{array}$ & $\begin{array}{l}\text { Stewarding and } \\
\text { nurturing } \\
\text { commercialization } \\
\text { of a breakthrough } \\
\text { technology }\end{array}$ & $\begin{array}{l}\text { Finding a balance } \\
\text { between use of } \\
\text { public resources, } \\
\text { IP management, } \\
\text { and advancing patient } \\
\text { treatment and } \\
\text { mitigating risk }\end{array}$ & $\begin{array}{l}\text { Health provider } \\
\text { required to effectively } \\
\text { manage the IP. } \\
\text { Success is dependent } \\
\text { on developing } \\
\text { organizational } \\
\text { competencies and } \\
\text { decision-making } \\
\text { frameworks to } \\
\text { support the cost of } \\
\text { IP management and } \\
\text { commercialization }\end{array}$ & $\begin{array}{l}\text { Faster commercial } \\
\text { development process, } \\
\text { reduced impact of } \\
\text { perceived opportunity } \\
\text { costs; inventors partner } \\
\text { with health care provider } \\
\text { in a safe environment to } \\
\text { refine the innovation }\end{array}$ & $\begin{array}{l}\text { Provide patients access } \\
\text { to technology and } \\
\text { expected benefits as } \\
\text { soon as possible; health } \\
\text { provider develops } \\
\text { competence and capacity } \\
\text { for IP management; } \\
\text { development of a } \\
\text { framework to support } \\
\text { translation of clinical } \\
\text { discovery into patient } \\
\text { and economic outcomes }\end{array}$ \\
\hline
\end{tabular}

Abbreviations: IP, intellectual property; SMEs, small and medium enterprises.

\section{Opportunities}

The LDP confirmed that technologies at any stage of development need to be dynamic and responsive to the lessons offered by real-life application. The technology developer, vendor, and health leaders are all critical to the successful implementation of technology solutions to address complex health care needs. Even when a product is deemed market ready, product improvement knowledge is often gleaned from clinical application. The GPS vendor integrates the feedback from LDP clients to improve their device, a result that benefits the vendor, the end user, and the health care system.

A key part of the LDP knowledge translation plan is building upon current interest from AHS leadership. For example, there is a recognized benefit to having access to technologies that can support Home Care clients to remain safe in the community setting or return to the community after involvement with the acute care system. Through the course of the LDP, a growing interest in technology's applicability in Continuing Care emerged among Seniors Health and AHS leaderships. Capitalizing on the momentum, the LDP and provincial leaderships have partnered to establish a provincial best-practice committee for technology use in Continuing Care. Given the unique client needs and service provision challenges that are often encountered, particularly in rural areas of the province, technology can offer alternative means of care provision or respite for clients and families at a cost deemed reasonable by leadership.

The LDP provides an opportunity for collaboration with multiple and diverse stakeholders, including Alberta Health (Continuing Care and Health Research Policy and Partnerships), Alberta Innovation and Advanced Education, Seniors Health Strategic Clinical Network, University of Alberta researchers, AHS Operations leaders, and the Alzheimer Society of Alberta. The Steering Committee was co-chaired by the Principal Investigator and the Executive Director, Seniors Health, and later the Director, Home Care Development. Further to that, project committees included operational stakeholders such as the Calgary Police Service, Grande Prairie Royal Canadian Mounted Police, Grande Prairie Primary Care Network, Home Care staff, and the GPS vendor. Communication and information sharing was consistent and routine during the course of the project. 
There is a need for ongoing research around technology implementation for Continuing Care in the intermediate and the long terms. Ongoing research into economic benefits to the health care system would further inform decision makers. For example, the LDP is crudely estimated to have helped the health care system avoid a total of $\$ 1,058,400.00$ Canadian dollars (2015) through the life of the project. In addition, the impact of the technology on clients, caregivers, and providers realized by the LDP is informing AHS's approach to technology implementation at the operational and policy levels.

\section{GRH: an institutional perspective Objectives}

For the rehabilitation component of health care, optimizing the functional abilities of individuals is increasingly reliant on the use of appropriate technologies. This requires the continual development of innovative ideas, products, and processes and is best facilitated through effective interactions among clinicians, physicians, patients, families, industrial or commercial concerns, researchers, and funding groups. Of these, the industrial/commercial partners, particularly, the small and medium enterprises (SMEs), appear very innovative, yet have difficulty gaining access to the health care system for the reasons stated earlier. As a result, the GRH with the assistance of the National Research Council Industrial Research Assistance program, ${ }^{27}$ a national program to accelerate research and innovation in commercialization, studied the barriers facing SMEs in gaining access and innovating with rehabilitation health care.

\section{Approach}

Over approximately 5 years, we gained further insight into how effective interactions could foster innovative concepts, products, or processes, either from clinical challenges within health care or from ideas developed externally by industry and/or academia. This progress led to two Reverse Trade Shows in which clinical staff presented their challenges to industry and academia. The result of this proactive approach to health care innovation and product/process development has given rise to $>25$ projects. Some of these have been deployed in clinical practice, some are in the development stage, and others have led to products in the precommercial stage or on the market. The experience to date has clearly identified difficulties, resource constraints, and long timelines facing the SME sector in moving from ideas to prototypes to potential products and then procurement within the health care system.
To illustrate our experience, consider the case of interactions with a local SME that began with development of an upper extremity rehabilitation system using a joystick coupled to computer-based games. The concept was to develop specific games that would engage the user in improving fine motor skills through games that targeted specific muscle groups. The games were to be designed with increased complexity to allow users to improve their abilities while the therapist could quantitatively measure their progress. The system went through numerous iterations, with patients and therapists evaluating each system and offering suggestions for the next version. After several years of development, a three-dimensional, joystick-activated workstation that allows complete three-dimensional movements coupled with the ability to twist and grasp was achieved and is now marketed worldwide (ReJoyce: http://www.rehabtronics.com).

During the latter stages of this development, another completely unrelated gaming system had been conceptualized by therapists within the GRH. The idea was to use a touchsensitive surface that would allow users to rehabilitate arms and hands through specialty games that could be tailored to work on specific deficits. First prototypes were designed and built through computing science students at the University of Alberta while the second version was produced through student projects at the Northern Applied Institute of Technology. The prototype was presented at the first Reverse Trade Show, for which the rehabilitation workstation group (Rehabtronics) decided to get involved. The result was a Rehabilitation Touch Screen system that included a suite of games and specialized styli (for individuals with limited hand function), mounted on a platform that was completely adjustable to various heights, allowing it to be accessible for a range of clients from children to adults and those in wheelchairs (ReTouch: http://www.rehabtronics.com).

\section{Challenges and opportunities}

A major challenge in our approach was securing the essential contribution of clinical and support staff at the GRH to engage in innovation activities with industry and academia due to demands of normal patient care activities. Further, many specialized talents necessary for moving the concept to prototype had to be sourced from outside both the SME and GRH. For some projects, these resources were met through various sources including external philanthropy, volunteer activity, and our academic partners. However, in many situations, the ideas and projects were stalled due to lack of funding, often losing any momentum generated from initial enthusiasm. Overcoming the numerous challenges 
required perseverance and innovative problem solving. The time required to complete the projects was much longer than expected due to limited and inflexible financial and human resources.

\section{Lessons learned}

The ReJoyce and ReTouch stories illustrate the necessity for both the "industrial push" and "clinical pull" aspects of innovation in health care. Without the ability to facilitate the interactions among the clinical, academic, and business worlds, health care innovation is frustrating and often leads to abandoned projects. For future expansion of these interactions, the GRH is proposing the establishment of a virtual hub that supports the development, assessment, and implementation of innovative ideas and optimizes the likelihood for potential commercialization. This approach, in which the health care system itself can be an economic engine, is in line with the Alberta Health Research and Innovation Strategy, wherein "economic benefits may include the advantages stemming from healthier Albertans as well as economic returns from commercialization of health research into applications, services, treatments and products". ${ }^{28}$ The Alberta Health Services Research and Innovation Strategy 2012-2017 mirrors this approach by supporting strategic research "aimed at solving specific problems of value to our population(s) of interest". ${ }^{29}$ It is believed that the development of this virtual hub, which combines the "pull" of clinical challenges and the "push" from industry, can effectively lead to fulfillment of the dual purposes of increased and diversified economic opportunities as well as better patient outcomes.

\section{Linac-MR: a medical device perspective}

The Linac-MR represents a promising and highly innovative approach to radiation therapy for cancer care, which addresses a known clinical challenge. Developed in Alberta by two medical physicists at the Cross Cancer Institute, the Linac-MR provides increased precision in targeting tumors. ${ }^{30}$ This innovation is expected to translate into fewer side effects and improved quality of life for the patient, coupled with a reduction in the number of radiation treatment appointments.

\section{Objective}

This case provides a unique opportunity to explore the role of a publicly funded health entity in managing the commercialization of a breakthrough technology. Over the course of developing the system, AHS, in partnership with the inventors, assumed all responsibility for development of the technology, including management of IP and the creation and execution of a subsequent commercialization strategy. Commercialization of high-value technologies by publicly funded enterprises elicits tensions surrounding fiduciary responsibility of public resources while facilitating patient access to a promising treatment. Our challenge is to carefully and appropriately manage risk along the innovation pathway.

\section{Opportunity}

Taking a nontraditional leadership role in the commercialization of this promising technology (licensing it to industry at the first possible moment), AHS can increase the probability that Albertans will be able to access and benefit from a technology that was developed in this province. Commercialization of the Linac-MR provides a valuable opportunity to develop a formal framework to test and support the translation of clinical discovery into better treatments and greater economic growth within the province. The development of this framework will support replication of this approach beyond the Linac-MR opportunity to include other novel technologies developed in Alberta, Canada, leveraging the public system to solve vexing problems via stewarding of technology commercialization (TC).

\section{Challenges and issues}

The legislative and regulatory frameworks for Canadian health care provider organizations have not typically assumed responsibility for filing and managing IP along with the subsequent actions required to commercialize promising technologies. Traditionally, the pursuit of commercial interests originating from public health system innovation has been considered a disparate and unrelated function from the primary mandate of providing patient-centered health care. As a consequence, public health systems have generally not developed the core competencies and decision-making structures required to pursue commercialization ventures. The paucity of these requisite skills and structures is a potential barrier to collaborating with private companies or investors experienced in commercializing novel health technologies, impeding the technology and commercial development process. Additionally, publicly funded health care providers face intense pressure related to opportunity costs when developing novel technologies. Specifically, commercialization is often perceived as peripheral from the primary mandate of providing clinical care. Therefore, the allocation of resources required to pursue commercialization is allocated away from frontline care and the system's governing mandate. The opportunity cost of pursuing commercial ventures suggests that public systems require a clear and precise understanding 
of the clinical, operational, and financial value underlying the novel technology. Finally, the inexperience with managing commercial ventures within public health systems precludes the opportunity to develop appropriate mechanisms to assess and manage the uncertainty associated with commercialization. As public systems do not have access to these mechanisms, they are generally uncomfortable with and unwilling to bear the risk required to pursue commercialization of promising health technologies.

\section{Approach}

In an attempt to counterbalance these recognized challenges, the AHS leadership has tasked a multidisciplinary working group to develop a commercialization strategy for the Linac-MR and mitigate associated risks. The team includes expertise and experience in commercialization, health system analysis, HTA, business valuation, and IP management. The working group has operated primarily to fill the existing "knowledge gap" within the organization related to commercialization expertise. As a function of providing this expertise, the Linac-MR working group has been able to provide senior organizational leadership with credible and experience-driven information as well as critical guidance on strategic decisions related to TC. Therefore, decision makers are provided with a greater degree of comfort in executing suggested strategic approaches. As a consequence of the Linac-MR working group's activities, nascent decisionmaking structures and experience within the organization are developing. The working group has also recognized the impact of perceived opportunity costs on development of the technology. Consequently, a comprehensive technology valuation approach has been initiated to determine whether the potential benefit of the technology surpasses required development resources allowing for an assessment of its marketplace value. Under this approach, the value of the technology will use a DCF model to attach a financial value to the operational capacity that the technology frees up by reducing the number of radiation appointments needed to treat patients. Finally, the working group has attempted to mitigate risk and uncertainty associated with commercialization by forming supplier and investment partnerships with external organizations. The formation of these partnerships has provided the working group with access to critical knowledge, expertise, and experience, which were not available within the organization.

\section{Lessons learned}

The Linac-MR project offers an important learning for publicly funded enterprises that are commercializing technologies. Although Canadian health care provider organizations are not currently well positioned to fully undertake and exploit the promise of innovations, it is possible for these organizations to play a significant role in moving innovative health technologies from the IP phase to the adoption phase with the intent to realize the clinical, operational, and financial benefits of the innovation. The most critical step in taking responsibility for this role is to develop organizational competencies and decision-making frameworks that support innovation and commercialization.

\section{Discussion: the value of innovation}

The relationship between HTA and TC has historically been characterized by competing objectives and misaligned incentives, impeding the adoption of novel technologies. HTA assumes a deliberate and measured approach to evaluating novel technologies for potential health system adoption. Under HTA, the decision-making timeframe is dictated by the availability of necessary evidence to ensure that the clinical gains realized by the novel technology surpass the health benefits lost from replacing an existing technology. Conversely, the decision-making process in TC is dictated by an external environment of extreme competition, with success characterized by swift market penetration and rapid expansion of market share. These competing objectives define a system in which companies rapidly innovate and develop novel health technologies to remain competitive but are met by a risk-averse health system that requires accumulation of evidence to support adoption. The sustainability of a continually improving health system requires methods focused on harmonization of these competing objectives to identify high-value technologies that can be adopted as early as possible for the benefit of patients and families.

\section{HTA: maximizing clinical value}

The primary objective of HTA is to maximize societal health benefit while meeting budget constraints. This is achieved through evaluation of a technology's underlying clinical value relative to its purchasing and operating costs. Clinical value is a patient's treatment outcome and health state relative to an existing comparator, which when aggregated captures the societal benefit. Societal perspective in health care systems is necessary when resource scarcity is a significant determinant of decision making and resource allocation. The decision criterion underlying adoption of health technologies from the societal perspective is that aggregate health benefit of the novel technology has to surpass the health benefit lost from the replaced technology. Societal health gain can also be maximized through optimal resource allocation strategies 
based on opportunity costs, whereby the opportunity cost of adopting technology $\mathrm{A}$ is the aggregate health benefit lost to society from no longer using technology B. Within this context, the clinical value of a novel technology is demonstrated via the incremental aggregate health benefit above the existing standard of care.

Clinical value of a novel technology is most relevant to reimbursement decision makers whose mandate is to determine whether the evidence is sufficient to support adoption and the subsequent allocation of scarce resources toward the novel technology and away from existing treatment modalities. A health economic evaluation is one type of evidence to be considered. It represents a systematic and rigorous approach that compares the health benefit gained per financial unit spent on a novel technology relative to an existing one. The resulting resource allocation efficiency measurement is derived by calculating the ratio of incremental costs and incremental health benefits between the novel technology and the existing standard of care. The ICER output reflects the net health gain (or loss) to society per incremental financial unit spent on providing care using the novel technology. Generally, if the resulting ICER is within a jurisdiction's willingness to pay threshold (WTP), the technology is adopted.

\section{TC: maximizing economic value}

\section{Maximizing economic value from the technology} company's viewpoint

In contrast to HTA, TC uses a business-based approach that seeks to maximize the net present value (NPV) of changes in future cash flows resulting from the introduction of the new health technology. From a private company's perspective, this process largely concentrates on maximizing shareholder value through the NPV and the potential return on investment.

In the commercial world, value is interpreted through an economic lens. Specifically, the cost of future product development needs to be counterbalanced by an adequate financial return. Successful commercialization of novel health technologies requires continuous investment and reinvestment of financial resources to achieve the forecast development milestones throughout the research-and-development process; this includes post-market launch development needs. Therefore, a technology with potential market value has to demonstrate sufficient economic benefit in a timely manner to counterbalance the uncertainty of achieving development milestones and the risk of lost investment capital.

The economic value of a technology can be calculated through numerous approaches. The most common is the DCF approach; it is based on the assumption that value is achieved through selling the product to an end user and requires proof that cash is being generated or has the potential to be generated at forecast levels. ${ }^{31}$ The DCF approach estimates anticipated free cash flows generated from the technology by offsetting estimated revenues against anticipated operational costs and accumulated investment expenses required to attain research-and-development milestones. The anticipated annual cash flows are discounted to reflect the time value of money and risk. The resulting DCF stream, the NPV, reflects the aggregated, time-adjusted economic value of the project.

\section{Maximizing economic value from the health care providers' viewpoint}

Traditionally, health care providers have focused primarily on clinical value and the dimensions of quality in making decisions to adopt promising new technologies. This is very different from the approach taken by industry, which consistently makes investments on the basis of real cash flow. As noted earlier, industry uses recognized financial practices (such as DCF and NPV) to guide decisions on whether to pursue commercialization of a new technology. Industry also uses these techniques to guide decisions on capital equipment or technology acquisitions. Health care providers in all sectors could benefit from applying similar business and financial techniques to guide their decisions in acquiring innovative health care technologies.

Health care providers could also benefit from giving consideration to the operational value proposition that new technology offers. For instance, the value proposition for an innovative health care technology may be that it will increase the provider's capacity to deliver a particular service more effectively than is currently possible with an existing market competitor's product. This advantage may translate into significant financial or operational gains. For instance, with the Linac-MR, the operational value proposition is that because the technology is expected to reduce the number of fractions (treatments) for patients, it will likely free up a significant amount of operational capacity within that cancer center. If this possibility is realized, the management team at an earlyadopting site would be presented with a range of managerial options. Their choices could include increasing the number of patients receiving treatment to reduced patient wait lists and/ or reduced operating hours to reflect the reduced number of treatment appointments needed to meet current demand. In a case wherein management chooses to reduce the center's operating hours, it may be possible to realize real gains in operating cash flow.

Just as a technology company must demonstrate economic value to their shareholders, health care providers could 
also demonstrate that their decision to acquire innovative new technologies will create economic value using the same financial techniques.

\section{Challenge of harmonization}

The misalignment of objectives between HTA and TC processes becomes most evident in product pricing decisions. In the medical device sector, product offerings encounter aggressive decay rates in profits due to entry of competitors launching similar products. IP protection can slow competition, however, a company with a novel product must move quickly, as IP protection provides a short window to maximize profit and recoup development expenditures. While private companies need to act quickly to maximize profit, this is diametrically opposed to the public health system's mandate of ensuring resources are efficiently allocated. As a result, corresponding pricing strategies used by companies are at risk of falling outside of required WTP thresholds, indicating that the technology does not provide sufficient health benefits for the incremental price. Given the significant investment required to launch a health technology, failure to address reimbursement agencies' WTP thresholds early in the product development cycle can have catastrophic consequences for the technology company's commercialization plans. A proposed solution to this challenge is to have the technology company integrate HTA principles within the early stages of the TC process. As evidenced by the MaRS EXCITE program in Ontario, introducing HTA evidence thresholds into the early stages of the product development process can mitigate risk for companies and increase the probability of successful technology adoption. ${ }^{16}$

On the purchasing side of the equation, investment decisions regarding innovative technologies are based on HTA results that consider the clinical and health economic impact of the technology (as measured by ICERs and WTP thresholds). Typically, in making these types of decisions, the focus is primarily on clinical impact. While budget impact analyses (BIAs) are conducted as part of a health economic analysis (HEA), these analyses are generally conducted at the organizational level and, as such, do not fully capture the operational and financial impact of the decision on the clinical business unit that is operationalizing the new technology. In other words, HTA approaches (ie, BIAs and HEAs) take an aggregate, global perspective and, as such, account for the impact of the technology at an organizational or societal level. By assessing the operational and financial impact at this global level, these HTA techniques may not be sufficiently granular to reflect the operational, financial, and cash flow impact on the specific end user who is adopting the new technology. A proposed solution to this challenge is to have health care providers integrate TC principles (DCF, NPV) with the HTA process. Introducing TC evidence thresholds into the early stages of the preprocurement decision could mitigate exposure to risk.

On the industry side, HTA bodies are often perceived as gatekeepers as the process guides decisions on the adoption and reimbursement of a novel technology, the outcome of which is a critical revenue driver for a health technology company. As HTA processes are conventionally initiated at the final stages of product development, prior to, or after, market launch, the timing can expose companies to significant financial risk. Failure to receive a satisfactory recommendation from a HTA body may lead to a company being unable to recoup the significant expenditures required to bring the product to market. Further, the traditional nature of competing interests between HTA and TC suggests a zero-sum relationship between public and private entities. Although there are exceptions (such as the Linac-MR case), the private sector most commonly owns the IP for innovative new technologies that will subsequently be adopted by the public health system. In these cases, the economic rent generated from the IP underlying a novel health technology is borne directly by the public system in the form of increased opportunity costs. That is, the gains assumed by one actor in the system are directly translated into losses by the complementary actor. However, a potential solution to mitigate the traditionally fractious relationship between public and private interests is to integrate HTA within the early stages of a company's product development cycle.

\section{Lessons for advancement: the way forward}

It is important to note that there is no single path from innovation to commercialization; innovative ideas must be allowed to originate and develop in various ways that will likely require a cultural shift within health organizations and health systems, but innovation and sustainable public health care can be, and should be, complementary. Our findings from the selected literature, three case studies, and discussion of opportunities to more closely align HTA and TC underline several important lessons on the challenge of reconciling the tension between delivery of publicly accountable health care services, innovation development, and commercialization. In addition to recommending that technology companies integrate HTA principles into their product development cycles earlier, we recommend a reciprocal approach in which health care providers integrate TC principles into 
their decision-making processes for acquiring promising new technologies. Rather than simply acquiring new technologies based on clinically and economically focused HTA results, we recommend that health care providers place more consideration on the impact that the new technology is expected to have on future cash flow requirements. Integration of HTA and TC principles and ensuring that both approaches are adopted by both parties could increase the probability that the new technology will be adopted for the clinical benefit of patients, and at the same time, for the financial benefit of technology companies, health care providers, and their stakeholders.

The LDP demonstrates that a newly emerging organization such as the AHS, with the encumbrances of legacy policies, practices, and constraints, has the opportunity to forge new processes and pathways aligned with the contemporary expectations of developing an innovative internal environment and collaborative relationships. Using a technology "pull" approach ensures that the needs of patients and clients (not commercial interests) are the priority, although the two do not have to be mutually exclusive. In fact, both patients at the GRH (Edmonton, Alberta, Canada) and local SMEs have benefited from the introduction of research and development directly into the health care system. Removal of the barriers between developers and end users allowed ideas and prototypes to be tested in the GRH facility, resulting in early feedback and judicious use of resources to develop technologies that meet the health system needs. Finally, the Linac-MR case demonstrates a conceptual, methodological, and practical approach that helps to reconcile the apparent chasm between HTA and TC.

There is a way forward in reconciling health care delivery and commercialization of innovation through harmonization of the quantitative techniques that are integral to HTA (ICER), industry (DCF and NPV), and reimbursement agencies (WTP) in a way that more effectively serves patients' needs and enhances the economic well-being of the community. The reciprocal appreciation of the public and private sectors serving citizens' unmet health needs should translate into an understanding and application of their respective quantitative techniques.

\section{Disclosure}

The authors report no conflicts of interest in this work.

\section{References}

1. Mossialos E, Wenzel M, Osborn R, Anderson C, editors. International Profiles of Health Care Systems. New York, NY: The Commonwealth Fund (US); 2015:164. [Report No: 1802].
2. Conference Board of Canada. How Canada performs: a report card on Canada. [Internet]. Ottawa: Conference Board of Canada; 2015 [cited March 19, 2015]. Available from: http://www.conferenceboard.ca/hcp/ default.aspx.

3. Prada G, Santaguida P. Exploring Technological Innovation in Health Systems. Ottawa, ON: Conference Board of Canada (Can); 2007:68. [Report No: 2098].

4. Coad L, Dimick S. Conflicting Forces for Canadian Prosperity. Examining the Interplay between Regulation and Innovation. Ottawa, ON: Conference Board of Canada (Can); 2010:52. [Report No: 3439].

5. Prada G. Innovation Procurement in Health Care: A Compelling Opportunity for Canada. Ottawa, ON: Conference Board of Canada (Can); 2011:54. [Report No: 4318].

6. Conference Board of Canada. Sustainability - What Does this Mean for Canada's Health and Health Care Systems? Draft. Ottawa, ON: Conference Board of Canada (Can); 2011:37.

7. Arshoff L, Henshall C, Juzwishin D, Racette R. Procurement change in Canada: an opportunity for improving system performance. Healthc Manage Forum. 2012;25(2):66-69.

8. Stanley G. Canada's Pathways Toward Global Innovation Success. Ottawa, ON: Conference Board of Canada (Can); 2008:52. [Report No: 2762]

9. Snowdon A, Zur R, Shell J. Transforming Canada into a Global Centre for Medical Device Innovation and Adoption. London, ON: Richard Ivey School of Business Centre for Health Innovation and Leadership (Can); 2011:52.

10. Health Technology Assessment international. Disinvestment and Early Awareness [Internet]: Edmonton: Health Technology Assessment international; 2014 [cited March 19, 2015]. Available from: http:// www.htai.org/interest-sub-groups/disinvestment-and-early-awareness. html.

11. Caulfield T. Sustainability and the balancing of the health care and innovation agendas: the commercialization of genetic research. Sask Law Rev. 2003;66:629-645.

12. Ontario Health Innovation Council. The Catalyst: Towards an Ontario Health Innovation Strategy. Toronto, ON: Ontario Health Innovation Council; 2014:25.

13. Tsoi B, Masucci L, Campbell K, Drummond M, O’Reilly D, Goeree R. Harmonization of reimbursement and regulatory approval processes: a systematic review of international experiences. Expert Rev Pharmacoecon Outcomes Res. 2013;13(4):497-511.

14. Richard-Roy D. Another face of healthcare innovation: commercialization. Healthc Q. 2005;8(4):8-9.

15. MaRS Discovery District. What is MaRS EXCITE? [Internet]. Toronto: MaRS Discovery District; 2015 [cited March 19, 2015]. Available from: http://www.marsdd.com/systems-change/mars-excite/mars-excite/.

16. MaRS Discovery District. The Value of MaRS EXCITE [Internet]. Toronto: MaRS Discovery District; 2015 [cited March 20, 2015]. Available from: http://www.marsdd.com/systems-change/mars-excite/ value-of-excite/.

17. Tsoi B, O’Reilly D, Masucci L, Drummond M, Goeree R. Harmonization of HTA-based reimbursement and regulatory approval activities: a qualitative study. J Popul Ther Clin Pharmacol. 2015;22(1):e78-e89.

18. Menon D, Stafinski T. Health technology assessment in Canada: 20 years strong? Value Health. 2009;12:S14-S19.

19. Banken R. Institut national d'excellence en santé et en services sociaux. Int Innov. 2014;131:16-17.

20. Institut national d'excellence en santé et en services sociaux (INESSS) [Internet]. About the Institute. Quebec: Institut national d'excellence en santé et en services sociaux; 2015 [cited March 20,2015]. Available from: https://www.inesss.qc.ca/en/about-us/about-the-institut.html.

21. Canadian Agency for Drugs and Technologies in Health. CADTH: Our History in the Making [Internet]. Ottawa: Canadian Agency for Drugs and Technologies in Health; 2015 [cited March 23, 2015]. Available from: http://www.cadth.ca/en/cadth/history.

22. Borowski H, Brehaut J, Hailey D. Linking evidence from health technology assessments to policy and decision making: the Alberta model. Int J Technol Assess Health Care. 2007;23(2):155-161. 
23. Born K, Sullivan T, Bear R. Restructuring Alberta's Health System [Internet]: Healthy Debate; 2013 [cited March 20, 2015]. Available from: http://healthydebate.ca/2013/10/topic/politics-of-health-care/ restructuring-alberta-health.

24. Alberta Health Services. Strategic Clinical Networks [Internet]. Edmonton: Alberta Health Services; 2015 [cited March 23, 2015]. Available from: http://www.albertahealthservices.ca/scn.asp.

25. Alary B. GPS Technology Provides Piece of Mind for Patients Suffering from Dementia [Internet]. Edmonton: University of Alberta Faculty of Rehabilitation Medicine; 2014 [cited March 20, 2015]. Available from:http://rehabilitation.ualberta.ca/about-us/communications-andmedia-relations/rehab-impact-report.

26. Alberta Advanced Education and Technology. Alberta's Continuing Care Health Technologies Road Map. Aging in the Right Place. Edmonton, AB: Government of Alberta (Can); 2009:409.

27. National Research Council Canada. Industrial Research Assistance Program [Internet]. Ottawa: National Research Council Canada; 2015 [cited March 20, 2015]. Available from: http://www.nrc-cnrc.gc.ca/eng/ irap/index.html.
28. Innovation and Advanced Education. Alberta's Health Research and Innovation Strategy [Internet]. Edmonton, AB: Government of Alberta (Can); 2010:32.

29. Juzwishin D. Alberta Health Services Research and Innovation Strategy [online]; 2015 [cited March 31, 2015]. [E-mail to Meghan Sebastianski (meghan.sebastianski@albertahealthservices.ab.ca)].

30. Alberta Health Services and Cancer Control Alberta. Linac-MR [Internet]. Edmonton: Cross Cancer Institute; 2015 [cited March 20, 2015]. Available from: http://www.mp.med.ualberta.ca/linac-mr/.

31. Copeland T, Koller T, Murrin J. Valuation: Measuring and Managing the Value of Companies. 2nd ed. Hoboken, NJ: John Wiley and Sons Inc.; 1994.

\section{Publish your work in this journal}

Innovation and Entrepreneurship in Health is an international, peer reviewed, open access journal publishing original research, reports, reviews and commentaries on innovation and entrepreneurship in health. Special focus will be given to the theory, process, and practice of innovation and entrepreneurship by individuals and organizations within the health care context globally. The manuscript management system is completely online and includes a very quick and fair peer review system, which is all easy to use. Visit http://www.dovepress.com/ testimonials.php to read real quotes from published authors.

Submit your manuscript here: http://www.dovepress.com/innovation-and-entrepreneurship-in-health-journal 